Athens Journal of Humanities \& Arts - Volume 9, Issue 3, July 2022 - Pages 211-232

\title{
Evaluating the Emotional Impact of Environmental Artworks Using Q Methodology
}

\author{
By Lesley Brook
}

\begin{abstract}
By engaging audience emotions, the creative arts can prompt people to consider societal issues in different ways and hence influence views and behaviours. While audience members bring their unique personal characteristics to the art experience, their emotional responses to art may be shared somewhat. To contribute to understanding audience emotional engagement, this empirical study investigates the emotional responses of viewers to an exhibition of environmental artworks. Q methodology is used with images to evaluate emotional responses to artworks, after the participants have experienced the exhibition. The 25 participants sorted 54 images from their strongest positive to strongest negative emotional responses to the artworks depicted, then described their emotional responses in a semi-structured interview. A wide range of emotions were reported by participants, including multiple and mixed positive and negative emotions to single artworks. Statistical analysis of participants' $Q$ sorts revealed five groups of participants who shared emotional responses to the artworks. Differences between the groups can be accounted for by the level of participants' prior experience of contemporary art and by the different ways in which participants perceive negative emotions. Variance within the groups is explained by personal influences contributing to differences in participants' emotional responses to the artworks.
\end{abstract}

\section{Introduction}

Giving people factual information about climate change and other human effects on the environment has been insufficient to achieve widespread population behaviour change. ${ }^{1}$ The arts may have an important role to play in engaging people and hence potentially influencing behaviours that reduce or mitigate the environmental effects of human activity. ${ }^{2}$ With the increasing concern about

*Research Projects Coordinator, Otago Polytechnic, New Zealand.

1. Laura Kim Sommer and Christian Andreas Klöckner, "Does Activist Art Have the Capacity to Raise Awareness in Audiences? - A Study on Climate Change Art at the ArtCOP21 Event in Paris," Psychology of Aesthetics, Creativity, and the Arts, 2019, https://doi. org/10.1037/aca0000247; Diego Galafassi et al., "“Raising the Temperature": The Arts on a Warming Planet," Current Opinion in Environmental Sustainability 31 (2018): 71-79; Ronald E. Rice, Stacy Rebich-Hespanha, and Huiru Zhu, "Communicating about Climate Change Through Art and Science," in Climate Change, Media \& Culture: Critical Issues in Global Environmental Communication (ed.) Juliet Pinto, Robert E. Jr. Gutsche, and Paola Prado (Bingley, UK: Emerald Publishing Limited, 2019), 129-154.

2. Lesley Duxbury, "A Change in the Climate: New Interpretations and Perceptions of Climate Change through Artistic Interventions and Representations," Weather Climate and Society 2, no. 4 (2010): 294-299; Galafassi et al., "“Raising the Temperature”: The Arts 
climate change in particular and urgency to act to minimise its effects, there is interest in understanding the contribution of the arts and how they might influence engagement with the issues and behaviour change. ${ }^{3}$

There are many ways in which art can influence behaviour and contribute to climate change transformation processes, engaging people's imaginations, emotions, values and beliefs and more. Galafassi et al. identified 'a need to research the actual agency and contribution of artistic processes in particular contexts of societal climate transformations.' ${ }^{4}$ This study helps meet that need with respect to emotional engagement with an exhibition of artworks related to the effects of human activity on our world.

An exhibition entitled The Complete Entanglement of Everything was held in Dunedin, New Zealand, from $26^{\text {th }}$ September to $2^{\text {nd }}$ October 2020 at the Dunedin School of Art, Otago Polytechnic. The curator was Bridie Lonie, Head of the Dunedin School of Art. Her aim was that the exhibition would explore the ways that creative media can 'give us space and time to negotiate what we feel' about climate change and wider issues of anthropic planetary changes. ${ }^{5}$ The exhibited artworks were selected by the curator because each expresses a response to the environmental effects of human activity. The aim of this study is to evaluate the emotional impact of the environmental artworks in this exhibition.

\section{Emotional Responses to Art}

Because of the influence of personal characteristics, emotional response to art is said to be unique to each person, yet Tinio and Gartus theorised that some

on a Warming Planet," 2018; Ulrike Hahn and Pauwke Berkers, Visualizing Climate Change: An Exploratory Study of the Effectiveness of Artistic Information Visualizations (World Art, 4 June 2020), 1-25; Rice, Rebich-Hespanha, and Zhu, "Communicating about Climate Change Through Art and Science," 2019; Liselotte J. Roosen, Christian A. Klöckner, and Janet K. Swim, "Visual Art as a Way to Communicate Climate Change: A Psychological Perspective on Climate Change-Related Art," World Art 8, no. 1 (2018): 85-110; Laura Kim Sommer et al., "“Pollution Pods": The Merging of Art and Psychology to Engage the Public in Climate Change," Global Environmental Change 59 (2019): 101992; Sommer and Klöckner, "Does Activist Art Have the Capacity to Raise Awareness in Audiences? - A Study on Climate Change Art at the ArtCOP21 Event in Paris," 2019.

3. Carolina Aragón, Jane Buxton, and Elisabeth Hamin Infield, "The Role of Landscape Installations in Climate Change Communication," Landscape and Urban Planning 189 (2019): 11-14; David J. Curtis, Nick Reid, and Ian Reeve, "Towards Ecological Sustainability: Observations on the Role of the Arts," SAPIENS 7, no. 1 (2014); Gabriella Giannachi, "Representing, Performing and Mitigating Climate Change in Contemporary Art Practice," Leonardo 45, no. 2 (2012): 124-131.

4. Galafassi et al., "'Raising the Temperature": The Arts on a Warming Planet," 2018.

5. Bridie Lonie, in The Complete Entanglement of Everything Exhibition Catalogue, by Dunedin School of Art (Dunedin, NZ: Otago Polytechnic, 2020). 
commonalities might be expected because everyone shares the same perceptual, cognitive and neurobiological systems. ${ }^{6}$ Participants in their empirical study had seen either of two exhibitions, or one of three artworks. Participants selected their dominant emotional response to the exhibition or artwork they had experienced, choosing from pairs of emotions: involvement/interest, amusement/laughter, pride/elation, happiness/joy, enjoyment/pleasure, tenderness/feeling love, feeling disburdened/relief, astonishment/surprise, longing/nostalgia, pity/compassion, sadness/despair, worry/fear, embarrassment/shame, guilt/remorse, disappointment/regret, envy/jealousy, disgust/repulsion, contempt/scorn, and irritation/ anger. The emotions reported by participants responding to the same phenomenon fell into clusters as expected.

Sommer and Klöckner asked viewers of environmental artworks about five positive and five negative emotions: ${ }^{7}$ happiness, hope, a sense of awe, surprise, inspiration/enthusiasm, guilt, sadness/disappointment, apathy/ helplessness, anger, and anxiety. Previous environmental psychology research had shown that these emotions were 'predictors of environmentally friendly behaviour'. People who had viewed any one of the 37 artworks were asked the extent to which the artwork brought up each of these feelings within them. The results showed that certain artworks elicited common responses, enabling the researchers to group the artworks accordingly.

Surveying people who had experienced the artwork Pollution Pods, Sommer, Swim, Keller and Klöckner asked about the same ten emotions to examine the association of the emotions with behavioural intentions. Participants reported both positive and negative emotions, but all emotional effects were small, as were associated changes in intentions regarding behaviour. ${ }^{8}$

It is instructive to look at the role of emotions and imagery more generally. While negative emotions may motivate people to change behaviour, ${ }^{9}$ both positive and negative emotions can influence engagement, and both are likely to be

6. Pablo P L Tinio and Andreas Gartus, "Characterizing the Emotional Response to Art Beyond Pleasure: Correspondence Between the Emotional Characteristics of Artworks and Viewers' Emotional Responses," in The Arts and The Brain: Psychology and Physiology Beyond Pleasure (ed.) Julia F. Christensen and Antoni Gomila, vol. 237, Progress in Brain Research (San Diego: Elsevier Science \& Technology, 2018), 319-342.

7. Sommer and Klöckner, "Does Activist Art Have the Capacity to Raise Awareness in Audiences? - A Study on Climate Change Art at the ArtCOP21 Event in Paris," 2019.

8. Sommer et al., "“Pollution Pods": The Merging of Art and Psychology to Engage the Public in Climate Change," 2019.

9. Daniel A. Chapman et al., "Climate Visuals: A Mixed Methods Investigation of Public Perceptions of Climate Images in Three Countries," Global Environmental Change 41 (2016): 172-182; Thijs Bouman et al., "When Worry about Climate Change Leads to Climate Action: How Values, Worry and Personal Responsibility Relate to Various Climate Actions," Global Environmental Change 62 (2020): 102061. 
needed, ${ }^{10} \mathrm{O}^{\prime}$ Neill and Nicholson-Cole have shown from two case studies that while fear can capture people's attention, it does not motivate people to take action with respect to climate change; fear is likely to distance or disengage people from climate change because they feel helpless and overwhelmed. ${ }^{11}$ However, hope does not necessarily motivate either; Ojala found that constructive hope, based on confidence that a positive goal is within reach, does operate as a motivator, whereas hope based on denial was negatively correlated with pro-environmental behaviour. $^{12}$

Portraying local effects of climate change, whether in art or other imagery, can increase engagement for some people by appealing to place attachment. ${ }^{13}$ Relating climate change to 'local environmental issues and personal concerns' is recommended by Lorenzoni, Nicholson-Cole and Whitmarsh in their report on barriers to engagement with climate change. ${ }^{14}$

The artwork Bird Yarns drew attention to such a specific and local effect of climate change. Burke, Ockwell and Whitmarsh used $Q$ methodology to investigate to what extent and how art influenced emotional engagement with climate change, shaping values, attitudes and beliefs and hence making behavioural change more likely. ${ }^{15}$ Thirty-six statements about behavioural, affective and cognitive responses to climate change were sorted by viewers of the artwork Bird Yarns along a scale from -4 to +4 , in a bell-shaped curve. Participants then explained their sorting decisions in their own words.

10. Roosen, Klöckner, and Swim, "Visual Art as a Way to Communicate Climate Change: A Psychological Perspective on Climate Change-Related Art," 2018; Sabine Roeser, "Risk Communication, Public Engagement, and Climate Change: A Role for Emotions," Risk Analysis 32, no. 6 (2012): 1033-1040.

11. Saffron O'Neill and Sophie Nicholson-Cole, "“Fear Won't Do It": Promoting Positive Engagement with Climate Change Through Visual and Iconic Representations," Science Communication 30, no. 3 (2009): 355-379.

12. Maria Ojala, "Hope and Climate Change: The Importance of Hope for Environmental Engagement Among Young People," Environmental Education Research 18, no. 5 (2012): 625-642.

13. Susanne C. Moser, "Communicating Adaptation to Climate Change: The Art and Science of Public Engagement when Climate Change Comes Home," Wiley Interdisciplinary Reviews: Climate Change 5, no. 3 (2014): 337-358; Chapman et al., "Climate Visuals: A Mixed Methods Investigation of Public Perceptions of Climate Images in Three Countries," 2016; Kath Merrick, The Power of Art to Engage the Public on the Impacts of Climate Change on the Coast (Western Australia: Curtin University, 2011).

14. Irene Lorenzoni, Sophie Nicholson-Cole, and Lorraine Whitmarsh, "Barriers Perceived to Engaging with Climate Change among the UK Public and Their Policy Implications," Global Environmental Change 17, no. 3-4 (2007): 445-459.

15. Miriam Burke, David Ockwell, and Lorraine Whitmarsh, "Participatory Arts and Affective Engagement with Climate Change: The Missing Link in Achieving Climate Compatible Behaviour Change?" Global Environmental Change 49 (2018): 95-105. 
Q methodology is a qualitative research method designed to study the personal psychological perspectives of the participants on a dimension of the study subject matter. Each participant's feeling becomes activity, captured in their $\mathrm{Q}$ sort - the unique way in which they sort a set of items selected by the researcher. Afterwards participants describe their responses to the items. Quantitative analysis then correlates the $\mathrm{Q}$ sort produced by each participant with every other participant's $Q$ sort, looking for patterns of similarity to identify shared perspectives and attitudes. ${ }^{16}$ Rather than grouping the artworks by participants' common emotional responses as in Sommer et al.'s study, a Q methodology study would group participants by common emotional responses to the artworks.

A qualitative method enables participants to describe their emotions in their own words rather than limiting them to a list. Tinio and Gartus summarise three problems with self-reporting emotions: it depends on the verbal ability of the research participants, it can be hard to identify the exact emotion felt, and there is no standard way to measure the intensity of the emotion. ${ }^{17} \mathrm{Q}$ methodology captures the intensity of the emotional response to each item relative to every other item being sorted, with the strongest responses at each end of the Q sort. The Q sort also captures participants' emotional responses before they are asked to articulate their reasons. However, $\mathrm{Q}$ methodology does depend upon the ability of research participants to reflectively identify and articulate their own emotional responses.

Q methodology can be used with images rather than statements. One of O'Neill and Nicholson-Cole's case studies asked participants to sort 32 climate change related images, 'first according to how personally important or unimportant the images made climate change seem; and second according to how able or unable the images made them feel to do anything about climate change. ${ }^{18}$ Sleenhoff, Cuppen and Osseweijer used Q methodology with 48 images to investigate people's emotions about moving from a petrol-based to biobased economy. ${ }^{19}$ Schultz, Fielding and Newton asked research participants to sort a $\mathrm{Q}$ set of environmental images three times, to explore positive/negative

16. Simon Watts and Paul Stenner, Doing Q Methodological Research: Theory, Method and Interpretation (Los Angeles, [Calif.], London: SAGE, 2012), 15, 32, 53, 82, 98.

17. Tinio and Gartus, "Characterizing the Emotional Response to Art beyond Pleasure: Correspondence between the Emotional Characteristics of Artworks and Viewers' Emotional Responses," 2018.

18. O'Neill and Nicholson-Cole, "“Fear Won't Do It": Promoting Positive Engagement with Climate Change Through Visual and Iconic Representations," 2009.

19. Susanne Sleenhoff and Patricia Osseweijer, "How People Feel Their Engagement Can Have Efficacy for a Bio-Based Society," Public Understanding of Science 25, no. 6 (2016): 719-736. 
emotional response to the images, personal relevance of the images, and congruence of the images with the topic. ${ }^{20}$

$\mathrm{Q}$ methodology can be used with artworks. William Stephenson, who developed Q methodology, ${ }^{21}$ had participants sort 50 postcards, each showing a coloured reproduction of a vase, from most to least aesthetically pleasing..22 More recently Beck asked 48 elementary students to sort images of famous artworks according to how strongly they liked or disliked them. ${ }^{23}$ The students did not see the original artworks or even full-size reproductions. According to Gauzente and Good Q methodology is appropriate to uncover similarities between participants' preferences despite response to art being highly subjective. ${ }^{24}$ Participating gallerists were shown A5-sized reproductions of 43 contemporary prints, then a Q set of 30 prints were sorted by members of the public according to the degree to which they would like to have the artwork with them. In that study the participants were subsequently shown 28 of the prints hung in an exhibition and invited to reassess their $\mathrm{Q}$ sort. Hahn and Berkers asked participants to sort 25 images according to how much each image made them feel climate change is important; the images included digital art and artistic information visualisations as well as other information visualisations, cartoons, and news photos. ${ }^{25}$

The literature suggests that a wide range of emotional responses to artworks are possible and that despite personal influences there can be similarities between people's responses to art. $\mathrm{Q}$ methodology is appropriate to study emotions, identifying groups of people who have similar emotional responses. It can be successfully used with a $Q$ set of images rather than statements, including images of artworks. This study appears to be the first to use Q methodology with images of artworks to investigate emotional responses, and the first to use images of artworks after the original artworks have been experienced by the participants.

20. Tracy Schultz, Kelly Fielding, and Fiona Newton, "Images that Engage People with Sustainable Urban Water Management," Science Communication 40, no. 2 (2018): 199227.

21. Watts and Stenner, Doing $Q$ Methodological Research: Theory, Method and Interpretation, 2012, 5.

22. W Stephenson, "The Inverted Factor Technique," British Journal of Psychology. General Section 26, no. 4 (1936): 344-361.

23. Paula D. Beck, "Using Works of Art to Give a Voice to Culturally Diverse Students: Q-Methodology Study," Journal for Leadership and Instruction 16, no. 2 (2017): 18-25.

24. Claire Gauzente and James M. M. Good, "Q Methodology, William Stephenson and Postdisciplinarity," in Postdisciplinary Knowledge, (ed.) Tomas Pernecky (Abingdon, Oxon; Routledge, 2019), 165-182.

25. Hahn and Berkers, "Visualizing Climate Change: An Exploratory Study of the Effectiveness of Artistic Information Visualizations," 2020. 


\section{Method}

With ethics approval, 25 participants were recruited from amongst those who had visited the exhibition. Purposive sampling is generally desirable in $\mathrm{Q}$ methodology to garner a variety of viewpoints. ${ }^{26}$ In this study, however, recruitment was necessarily limited to adults who had attended the exhibition, were interested in participating, and were available to meet the researcher. In Q methodology as few as 15 or even 11 participants can be enough, ${ }^{27}$ and in this case the number of participants was limited to the number of interviews that one researcher could realistically undertake while the exhibition was a recent memory for participants.

Participants had a wide range of ages and levels of experience with contemporary art. Only $24 \%$ of participants were male. Willingness to discuss their emotional response to the exhibition may have influenced the gender mix of participants, but records of exhibition attendance are not available for comparison. While $84 \%$ of study participants identified only with European ethnicity, this is consistent with the 2018 New Zealand census: $86.6 \%$ of the residents of Dunedin City identified with the European ethnic group..$^{28}$

Because the exhibition was of environmental artworks, participants were asked how they felt about the effects of human activity on our world, which part of the city they lived in, and which other part of the city they spent most time in. Twenty four of the 25 participants reported negative feelings about the effects of human activity on our world. Participants resided and spent time in a wide range of locations across the city. Participants were asked how much they attended of the symposium, Mapping the Anthropocene in Otepoti/Dunedin, held over the weekend 26/27 September and incorporating the exhibition opening.

Within two weeks of the exhibition closing the researcher met with all participants individually. After providing informed consent to the study, each participant completed a $\mathrm{Q}$ sort of 54 photographs of all the artworks according to their emotional response to the artwork/s shown. The sorting was from -5 for the strongest negative emotional response on the participant's far left to +5 for the strongest positive emotional response on the participant's far right, with one photograph each for -5 and +5 , three photographs each for -4 and +4 , four

26. Watts and Stenner, Doing Q Methodological Research: Theory, Method and Interpretation, 2012, 70-71.

27. Burke, Ockwell, and Whitmarsh, "Participatory Arts and Affective Engagement with Climate Change: The Missing Link in Achieving Climate Compatible Behaviour Change?" 2018; Hahn and Berkers, "Visualizing Climate Change: An Exploratory Study of the Effectiveness of Artistic Information Visualizations," 2020.

28. Statistics NZ Tatauranga Aotearoa, 2018 Census Place Summaries - Dunedin City. Retrieved from: https:/www.stats.govt.nz/tools/2018-census-place-summa ries/dunedincity. [Accessed 7 January 2021.] 
photographs each for -3 and +3 , six photographs each for -2 and +2 , eight photographs each for -1 and +1 and ten photographs for 0 in the centre. Each $Q$ sort was followed immediately by a semi-structured interview. Participants were asked about their four strongest positive and four strongest negative emotional responses plus any additional artworks to which they had reacted during the sorting.

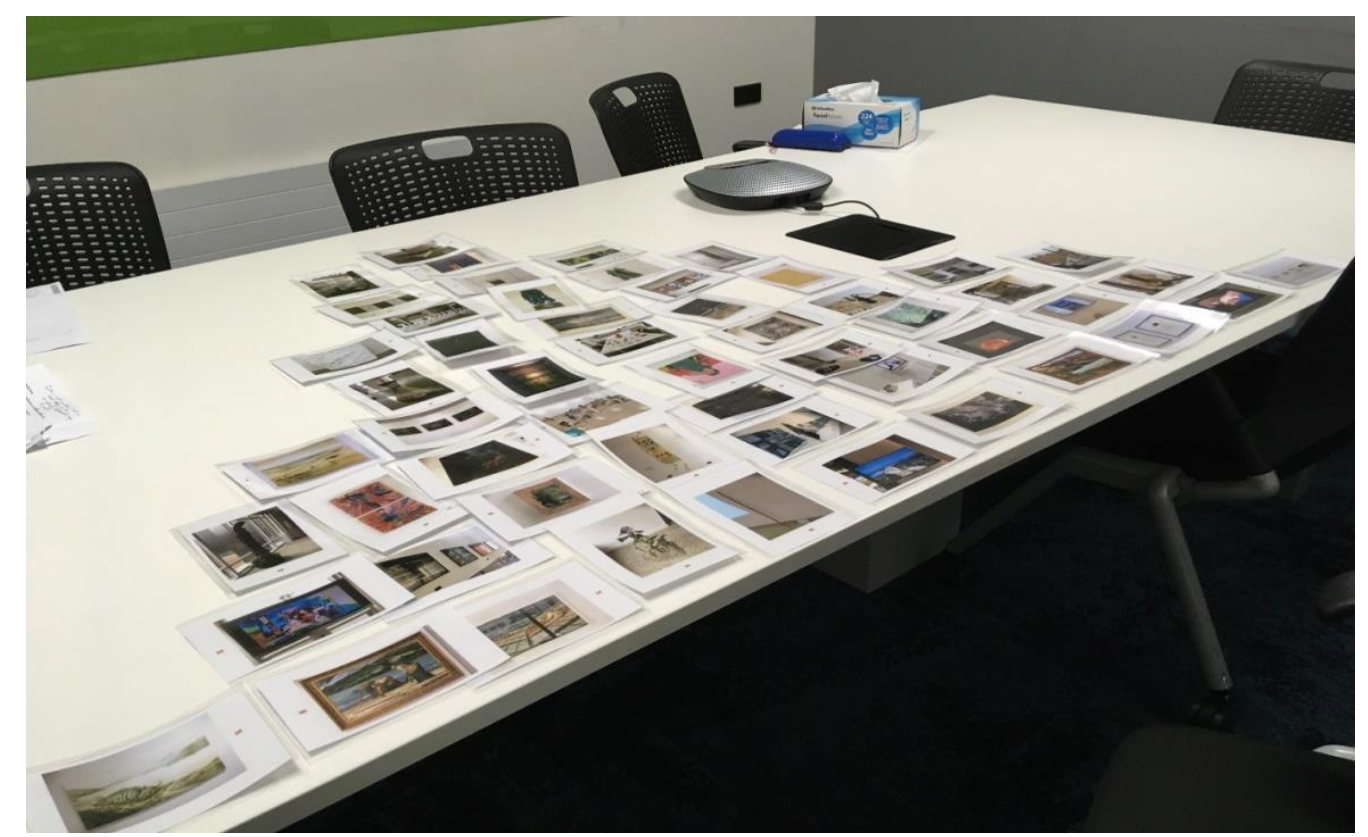

Figure 1. Illustrative $Q$ Sort by the Researcher of the Numbered Photographs Used in the Study

Source: The Author, 2020.

Q sort data were analysed using the software PQMethod ${ }^{29}$ and Centroid Factor Analysis, to identify patterns amongst the $25 \mathrm{Q}$ sorts and hence groups of participants who shared similar emotional responses to the artworks. Each such group is represented by a factor. Negative factor loadings indicate the opposite emotional responses. With 54 photographs the significant factor loading was 0.35 for the $p<0.01$ significance level..$^{30}$ The resulting five factors all had eigenvalues of greater than 1, satisfying the Kaiser-Guttman criterion. ${ }^{31}$ After varimax rotation to improve factor definition, 21 of the $25 \mathrm{Q}$ sorts were significantly loaded on one of the five factors, three $Q$ sorts were confounded (significantly loading on more than one factor) and one $Q$ sort was not significantly loaded on any factor. Table 1 shows the participants grouped by factor. The rotated factors explained $40 \%$ of the variance.

29. Peter Schmolck, PQMethod. Retrieved from: http://schmolck.org/qmethod/. [Accessed 30 October 2020.].

30. Watts and Stenner, Doing Q Methodological Research: Theory, Method and Interpretation, 2012, 107.

31. Ibid, 104-105. 
Table 1. Demographic Information for Participants Grouped by Factor

\begin{tabular}{|c|c|c|c|c|c|c|c|c|c|c|c|c|c|}
\hline & \multicolumn{7}{|c|}{ Factor $1 Q$ sorts } & \multicolumn{6}{|c|}{ Factor $2 \mathrm{Q}$ sorts } \\
\hline & A & $\mathrm{B}$ & $\mathrm{C}$ & $\mathrm{D}$ & $\mathrm{E}$ & $\mathrm{F}$ & G & $\mathrm{H}$ & $\mathrm{I}$ & $\mathrm{J}$ & $\mathrm{K}$ & $\mathrm{L}$ & $\mathrm{M}$ \\
\hline $\begin{array}{l}\text { Loading on } \\
\text { Factor }\end{array}$ & 0.92 & 0.71 & 0.60 & 0.59 & 0.35 & -0.41 & -0.52 & 0.61 & 0.60 & 0.55 & 0.54 & 0.41 & 0.38 \\
\hline $\begin{array}{l}\text { Contem- } \\
\text { porary art } \\
\text { experience }\end{array}$ & some & minimal & minimal & some & extensive & extensive & extensive & extensive & extensive & extensive & extensive & extensive & some \\
\hline $\begin{array}{l}\text { Symposium } \\
\text { attendance }\end{array}$ & All & None & Half day & $\begin{array}{c}\text { Exhibition } \\
\text { opening }\end{array}$ & One day & None & $\begin{array}{l}\text { Performance } \\
\text { only }\end{array}$ & All & None & Most & One day & One day & None \\
\hline Age & 22 & 27 & 32 & 71 & 26 & 52 & 48 & 23 & 61 & 56 & 66 & 57 & 55 \\
\hline Gender & $\mathrm{F}$ & $\mathrm{F}$ & $\mathrm{M}$ & $\mathrm{F}$ & $\mathrm{F}$ & $\mathrm{F}$ & $\mathrm{F}$ & $\mathrm{F}$ & $\mathrm{F}$ & $\mathrm{M}$ & $\mathrm{M}$ & $\mathrm{M}$ & $\mathrm{F}$ \\
\hline Ethnicity & Asian & $\begin{array}{l}\text { Fijian } \\
\text { NZer }\end{array}$ & Europ'n & Europ'n & $\begin{array}{l}\text { Māori / } \\
\text { Europ'n }\end{array}$ & Europ'n & Europ'n & Europ'n & Europ'n & Europ'n & Europ'n & $\begin{array}{l}\text { Jewish / } \\
\text { Europ'n }\end{array}$ & Europ'n \\
\hline
\end{tabular}

\begin{tabular}{|c|c|c|c|c|c|c|c|c|c|c|c|c|}
\hline & \multicolumn{4}{|c|}{ Factor 3 Q sorts } & \multicolumn{2}{|c|}{ Factor $4 \mathrm{Q}$ sorts } & \multicolumn{2}{|c|}{ Factor 5 Q sorts } & \multicolumn{3}{|c|}{ Confounded Q sorts } & \multirow[b]{2}{*}{$\mathrm{Y}$} \\
\hline & $\mathrm{N}$ & $\mathrm{O}$ & $\mathrm{P}$ & $Q$ & $\mathrm{R}$ & $\mathrm{S}$ & $\mathrm{T}$ & $\mathrm{U}$ & $\mathrm{V}$ & $\mathrm{W}$ & $x$ & \\
\hline $\begin{array}{l}\text { Loading on } \\
\text { Factor }\end{array}$ & 0.65 & 0.59 & 0.44 & 0.52 & 0.54 & 0.44 & 0.54 & 0.41 & $\begin{array}{l}0.42(\mathrm{~F} 3) \\
0.46(\mathrm{~F} 5)\end{array}$ & $\begin{array}{c}0.58(\mathrm{~F} 2) \\
-0.39(\mathrm{~F} 5) \\
\end{array}$ & $\begin{array}{l}0.39(\mathrm{~F} 2) \\
0.58(\mathrm{~F} 5) \\
\end{array}$ & - \\
\hline $\begin{array}{l}\text { Contemp- } \\
\text { orary art } \\
\text { experience }\end{array}$ & extensive & extensive & some & extensive & minimal & some & extensive & extensive & extensive & some & extensive & extensive \\
\hline $\begin{array}{l}\text { Symposium } \\
\text { attendance }\end{array}$ & All & All & None & One day & None & None & Half day & All & All & None & All & One day \\
\hline Age & 42 & 51 & 41 & 56 & 79 & 60 & 29 & 54 & 49 & 58 & 45 & 22 \\
\hline Gender & $\mathrm{M}$ & $\mathrm{F}$ & $\mathrm{F}$ & $\mathrm{M}$ & $\mathrm{F}$ & $\mathrm{F}$ & $\mathrm{F}$ & $\mathrm{F}$ & $\mathrm{F}$ & $\mathrm{F}$ & $\mathrm{F}$ & $\mathrm{F}$ \\
\hline Ethnicity & Europ'n & Europ'n & Europ'n & Europ'n & Europ'n & Europ'n & Europ'n & Europ'n & Europ'n & Europ'n & Europ'n & Europ'n \\
\hline
\end{tabular}

Source: The Author. 
Each factor denotes the shared emotional responses of the participants whose Q sorts significantly load on that factor, and is represented in a factor array. From the factor arrays in Table 2 the defining artworks for each factor can be identified - those that are ranked $+5,+4,-4$ or -5 , and those that are ranked highest or lowest compared with the other factor arrays. ${ }^{32}$ Six artworks were mentioned in interview by 12 or more of the 25 participants, either because they were amongst the strongest positive and negative emotional responses or in answer to subsequent questions, so these six artworks were also included as defining artworks for every factor.

Table 2. Factor Arrays for the Five Factors Extracted After Varimax Rotation, with Signature Artworks Asterisked

\begin{tabular}{|c|c|c|c|c|c|c|}
\hline $\begin{array}{l}\text { Artwork } \\
\#\end{array}$ & Artist/s & Factor 1 & Factor 2 & Factor 3 & Factor 4 & Factor 5 \\
\hline 1 & Small Measures & -1 & -3 & 2 & -4 & 2 \\
\hline 2 & $\begin{array}{c}\text { Janet de Wagt Hay } \\
\text { Wain }\end{array}$ & 4 & 0 & -1 & 2 & -4 \\
\hline 3 & $\begin{array}{c}\text { Jenna Packer } \\
\text { Riders }\end{array}$ & 3 & 3 & 1 & 2 & -2 \\
\hline 4 & $\begin{array}{c}\text { Heramaahina } \\
\text { Eketone }\end{array}$ & 2 & -3 & 0 & -2 & 0 \\
\hline 5 & Marilynn Webb & 4 & -1 & 3 & 2 & 3 \\
\hline 6 & Barry Cleavin & -2 & 0 & 3 & 0 & 0 \\
\hline 7 & Graham Fletcher & 1 & -3 & 1 & 3 & 2 \\
\hline 8 & Madison Kelly & 1 & 2 & -1 & 0 & 4 \\
\hline 9 & Adrian Hall & 1 & 2 & 2 & -3 & 1 \\
\hline 10 & Janine Randerson & -1 & 2 & 3 & -1 & 0 \\
\hline 11 & $\begin{array}{l}\text { Pam McKinlay \& } \\
\text { Henry Greenslade }\end{array}$ & 3 & 2 & 0 & 0 & 3 \\
\hline 12 & $\begin{array}{c}\text { Miranda Joseph } \\
\text { (in corridor) }\end{array}$ & 0 & -1 & -2 & -1 & -1 \\
\hline 13 & Sharon Singer & -2 & 1 & 3 & -3 & 1 \\
\hline 14 & Mark Bolland & -1 & 0 & 4 & 0 & 1 \\
\hline 15 & $\begin{array}{c}\text { Jenna Packer } \\
\text { Harbourside }\end{array}$ & -3 & 4 & 1 & -2 & -1 \\
\hline 16 & Lucinda King & -1 & 0 & 0 & -3 & -2 \\
\hline 17 & Steev Peyroux & 5 & 3 & 2 & 2 & -3 \\
\hline 18 & $\begin{array}{l}\text { Miranda Joseph } \\
\text { (in classroom) }\end{array}$ & 3 & 0 & 0 & 1 & 1 \\
\hline 19 & Scott Eady & 0 & -2 & 0 & 1 & 0 \\
\hline 20 & Michael Morley & 2 & -5 & -4 & -3 & 2 \\
\hline 21 & Textiles Year 1 & 3 & 2 & -2 & 0 & 4 \\
\hline 22 & Tim Barlow & 1 & 0 & 2 & -1 & -1 \\
\hline 23 & Peter Wheeler & -3 & -3 & -4 & -4 & -3 \\
\hline 24 & Charlotte Parallel & -2 & -1 & 0 & 1 & 0 \\
\hline 25 & $\begin{array}{c}\text { Ruth Evans } \\
\text { Poroporo }\end{array}$ & 2 & 1 & 4 & 4 & 3 \\
\hline
\end{tabular}

32. Ibid, 153-154. 
Athens Journal of Humanities $\mathcal{E}$ Arts

\begin{tabular}{|c|c|c|c|c|c|c|}
\hline 26 & $\begin{array}{l}\text { Alexandra } \\
\text { Kennedy }\end{array}$ & 1 & 1 & 2 & 1 & 0 \\
\hline 27 & Rob Cloughley & -1 & -1 & 0 & 2 & -1 \\
\hline *28 & Esta de Jong & -4 & 2 & -2 & 5 & -2 \\
\hline 29 & $\begin{array}{l}\text { Brendon Jon } \\
\text { Philps }\end{array}$ & 0 & -2 & -3 & -1 & -1 \\
\hline 30 & $\begin{array}{c}\text { Kristin O'Sullivan } \\
\text { Peren }\end{array}$ & -2 & 1 & 1 & -5 & -1 \\
\hline 31 & Jane Venis & -1 & 0 & -1 & 4 & -2 \\
\hline 32 & $\begin{array}{c}\text { Meg Brasell-Jones, } \\
\text { Pam McKinlay et } \\
\text { al. }\end{array}$ & -1 & -2 & -3 & 2 & -3 \\
\hline *33 & Toothfish & -5 & 4 & -2 & -2 & 5 \\
\hline 34 & Simon Swale & 0 & 0 & 1 & 1 & -2 \\
\hline 35 & David Green & -2 & 1 & -3 & -3 & -1 \\
\hline 36 & Neville Cichon & -2 & 0 & -1 & -1 & 1 \\
\hline 37 & Peter Nicholls & 0 & -1 & -1 & -1 & 0 \\
\hline 38 & Michael Greaves & 1 & -1 & -1 & -1 & 0 \\
\hline 39 & $\begin{array}{c}\text { Blair Thomson \& } \\
\text { Thomas Lord } \\
\end{array}$ & 0 & -2 & -2 & -4 & -2 \\
\hline$* 40$ & Michele Beevors & -4 & 5 & 4 & 1 & -5 \\
\hline 41 & Sue Pearce & 0 & 1 & -1 & 0 & -1 \\
\hline 42 & Christine Keller & 2 & 4 & 0 & 3 & 2 \\
\hline 43 & Neil Emmerson & -1 & -1 & 0 & -1 & 1 \\
\hline 44 & $\begin{array}{l}\text { Louise Beer \& } \\
\text { John Hooper }\end{array}$ & 2 & -4 & 1 & 0 & 2 \\
\hline 45 & $\begin{array}{l}\text { Janet de Wagt } \\
\text { Plastic Gleaners }\end{array}$ & 4 & 1 & 0 & 2 & -4 \\
\hline 46 & $\begin{array}{c}\text { Marion } \\
\text { Wassenaar } \\
\end{array}$ & -3 & 3 & -4 & 1 & 2 \\
\hline 47 & Andrew Last & 0 & -4 & 5 & 0 & 3 \\
\hline 48 & Eleanor Cooper & 1 & -2 & 2 & 0 & 1 \\
\hline 49 & Becky Cameron & 2 & -2 & -3 & 1 & 0 \\
\hline 50 & Johanna Zellmer & 0 & 1 & -1 & -3 & 0 \\
\hline 51 & $\begin{array}{c}\text { Ruth Evans Go } \\
\text { Mine! }\end{array}$ & 1 & 3 & -2 & -2 & 4 \\
\hline 52 & $\begin{array}{c}\text { Zero - NZ Arts } \\
\text { Incubator }\end{array}$ & 0 & 0 & 1 & 4 & -3 \\
\hline 53 & $\begin{array}{c}\text { Rachel Hope } \\
\text { Allan } \\
\end{array}$ & -3 & -1 & 1 & 0 & 0 \\
\hline 54 & James Robinson & -4 & -4 & -5 & 2 & -4 \\
\hline
\end{tabular}

Source: The Author. 


\section{Results}

Descriptions of the emotional impact represented by each factor were compiled using interview data from the participants whose $Q$ sorts significantly loaded on the factor, and also from participants whose $Q$ sorts were confounded. The emotions they identified, and their comments on the defining artworks for each factor, were scanned for words and near synonyms that were used by two or more participants. With the exception of one participant whose emotional responses aligned closely with Factor 1 (92\% loading), words used by only one participant were ignored because the factors together explained only $40 \%$ of the variance between $\mathrm{Q}$ sorts. Three artworks with the greatest disagreement between the five factors help to explain the different emotional responses represented by the factors. These signature artworks are marked with an asterisk in Table 2.

\section{Factor 1: Emotional Impact of Connection and Confrontation}

The positive emotional impact of environmental artworks on participants represented by Factor 1 included a sense of connection, calm, wonder, hope, and surprise. These participants responded positively to beauty. Environmental artworks which were in some way confronting or stark had a negative emotional impact. These participants also responded negatively to works that made them feel overwhelmed, sadness, grief or revulsion. This group responded very negatively to all three of the signature artworks illustrated in Figures 2, 3 and 4 . Participants in this group were likely to have little experience of contemporary art, whatever age they might be.

\section{Factor 2: Emotional Impact of Complexity and Boredom}

The positive emotional impact of environmental artworks on Factor 2 participants was hopefulness, being able to relate in some way to the work, and being made to smile. They responded positively to artworks for getting them thinking, admiration for the artist's skill, and appreciation for the amount of work by the artist. A message that resonated with them, including explicit messages, also elicited a positive emotional response. They responded positively to all the signature artworks, especially those shown in Figures 2 and 4. Artworks which did not succeed in engaging the participants had a negative emotional impact and were considered boring. Work considered masculine, conveying anger, annoying them or making them feel revulsion also elicited negative emotional responses. These participants can see beauty in works to which they responded negatively, but they also have positive emotional responses to works which they considered freaky, horrifying and sad. Participants in this group were likely to be in their 50 s or 60 s and very experienced with contemporary art. They tended to 
have a more pessimistic view of humankind's ability to avoid environmental disaster.

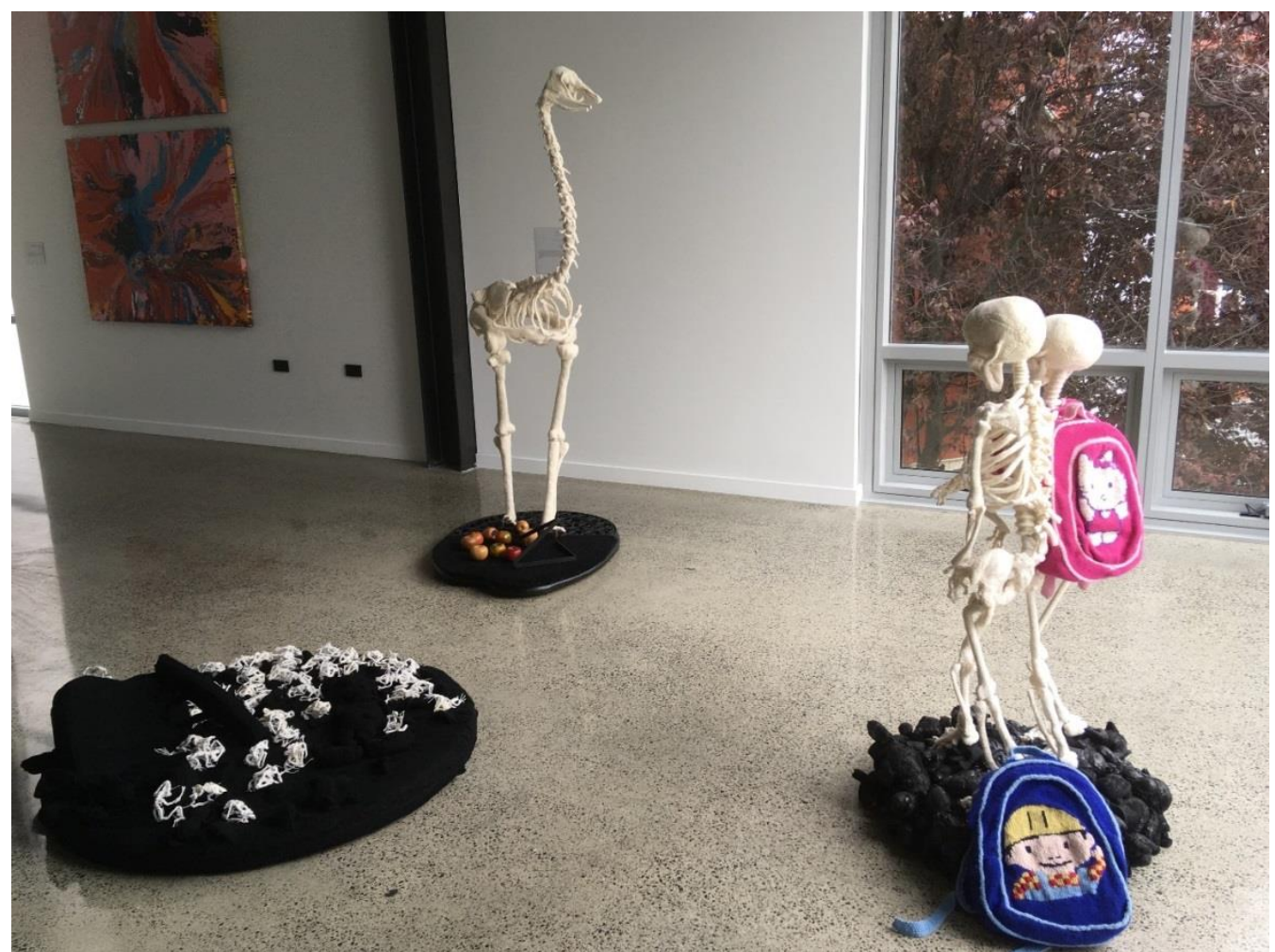

Figure 2. Tales of Sorrow and Regret and Wanderer: Dromaius Novaehollandiae and Last Plague, Wool and Mixed Media, Michele Beevors (Artwork 40 in this Study) Source: The Author, 2020.

\section{Factor 3: Emotional Impact of Amusement and Bleakness}

The positive emotional impact of environmental artworks on participants represented by Factor 3 included appreciation of humour, nostalgia, hope, and beauty. They were interested in materials and had strong positive emotional responses to works they felt made a connection for them, for example to place or people. They had a strong positive emotional response to only one of the signature artworks, shown in Figure 2. Artworks which made them feel bleak or depressing or revulsion had a negative emotional impact. They also responded negatively to works which did not engage them. Unattractive colours discouraged engagement. The artist's message could also evoke a negative emotional response, for example if that was considered too simplistic or not constructive. Factor 3 represents the emotional perspective of someone who is likely to be in their 40s or 50s with at least moderate experience with contemporary art. Like Factor 2, they tended to have a more pessimistic view of humankind's ability to avoid environmental disaster. 


\section{Factor 4: Emotional Impact of Happiness and Valuelessness}

Artworks that make them feel happy had a positive emotional impact on participants represented by Factor 4 . They were curious about materials. They responded negatively to artworks that seemed to them to have no value. They had a strong positive emotional response to one of the signature artworks, shown in Figure 3. Factor 4 participants were in their 60 s or 70 s and had little experience with contemporary art.

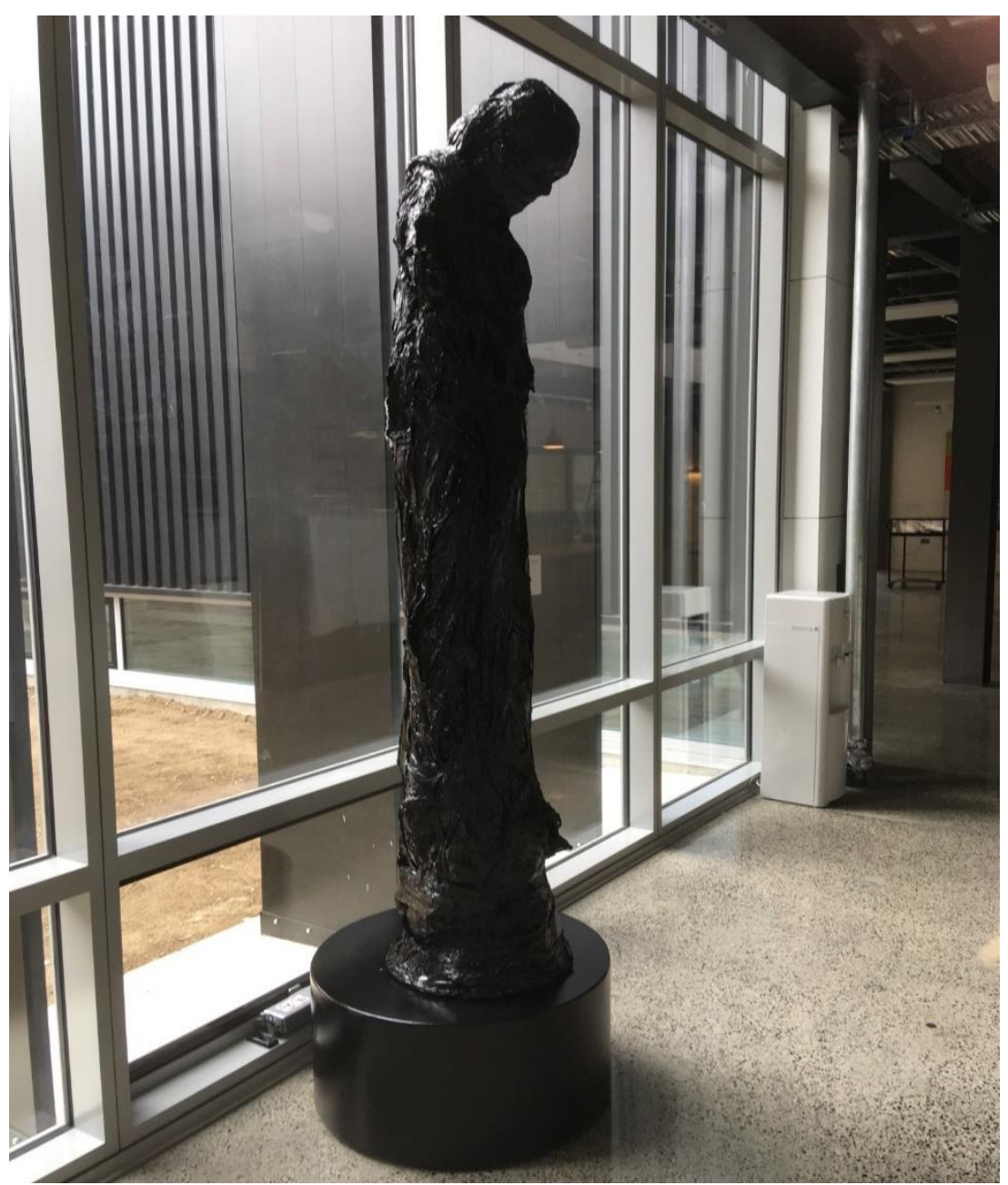

Figure 3. Figure from Becoming Darkness, Esta de Jong (Artwork 28 in this Study) Source: The Author.

\section{Factor 5: Emotional Impact of Beauty and Discomfort}

The positive emotional impact on participants represented by Factor 5 came from artworks that are considered beautiful or aesthetically pleasing, or made them feel connected with others. The participants appreciate humour. They are likely to have strong negative emotional responses to artworks that make them 
feel uncomfortable and are also not considered beautiful. Sadness can be positive or negative, and they appreciate skill in artworks whether they have a positive or negative emotional response. They had a strong positive emotional response to the artwork shown in Figure 4, and a strong negative emotional response to the artwork shown in Figure 2. These participants had a lot of experience with contemporary art, but no similarity in age.

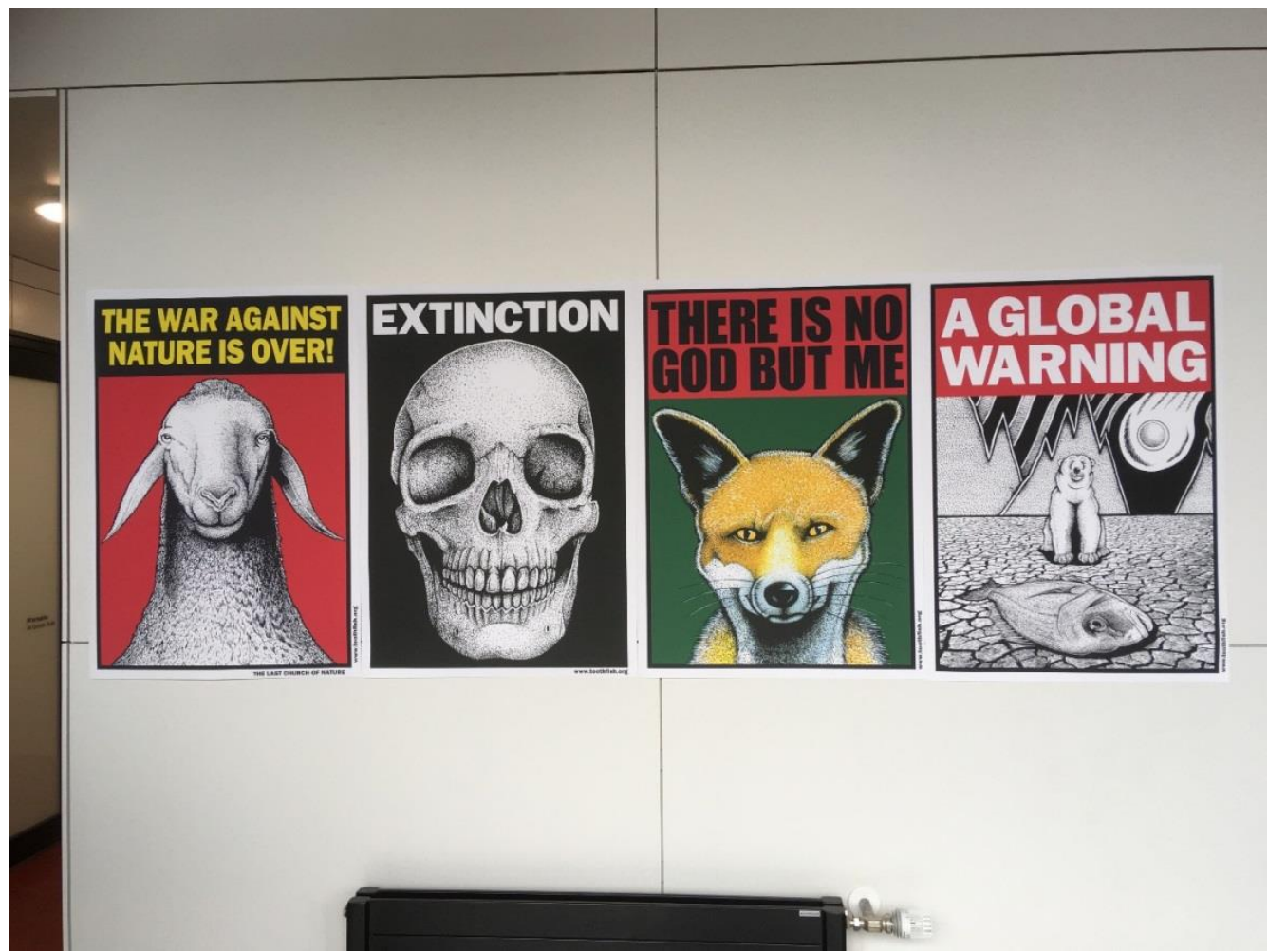

Figure 4. Posters, Toothfish (Artwork 33 in this Study)

Source: The Author.

\section{Discussion}

Participants in this study were asked about their emotional response to the four artworks to which they had the strongest positive emotional response and the four artworks to which they had the strongest negative emotional response. They reported a wide variety of emotions including all the emotions in Sommer et al.'s study,,$^{33}$ and all those used by Tinio and Gartus ${ }^{34}$ with two

33. Sommer et al., "“Pollution Pods": The Merging of Art and Psychology to Engage the Public in Climate Change," 2019.

34. Tinio and Gartus, "Characterizing the Emotional Response to Art Beyond Pleasure: Correspondence Between the Emotional Characteristics of Artworks and Viewers' Emotional Responses," 2018. 
exceptions, feeling disburdened/relief and envy/jealousy. Additional emotions reported by participants included horror/creepiness, calm/soothing, shock/ feeling confronted, curiosity, stress, pain, confused, uncomfortable, admiration, unengaged/boredom.

Participants often described more than one emotion in relation to one artwork, and at times named both positive and negative emotions. For example, one participant ascribed feelings of 'sadness' and 'optimism' to an artwork to which that participant had a strong positive emotional response, while another used 'beautiful' as well as 'bleak' in relation to an artwork to which that participant had a strong negative emotional response.

Some participants found it more difficult than others to identify the emotion/s they were feeling, a known problem with self-reporting emotions. ${ }^{35}$ In the process of identifying their emotional response many began by discussing the artwork. Nevertheless, the number and variety of emotions reported by participants in this study suggests that a qualitative study has a valuable contribution to make to our understanding of emotional responses to artworks. In future qualitative studies, participants might find it helpful to have a list of emotions, without limiting them either to the emotions listed or to only one emotion.

This study confirms that there are commonalities in emotional responses to artworks, as Tinio and Gartus expected. ${ }^{36} \mathrm{Q}$ methodology extracted five factors, i.e., five groups of participants with similar emotional responses, accounting for 21 of the 25 participants. Differences in ethnicity, gender, symposium attendance and location did not appear to be associated with the different groups.

Two key features appear to distinguish the five groups of participants. The first was degree of experience with contemporary art. Art knowledge and expertise influences emotional response to art; those with a higher level of knowledge and experience, whether that is gained from formal education and/or informal exposure to art, prefer art that is more difficult to engage with. ${ }^{37}$ In this qualitative study participants were asked to describe their previous experience with contemporary artworks such as the ones in this exhibition. To clarify this if necessary, some participants were asked related questions, for example how often they would go to an exhibition of contemporary art. Three participants had minimal experience, some would attend an exhibition of contemporary art perhaps once or twice a year, others as often as once or twice a month. Many participants who were experienced with contemporary art also reported some combination of the following experiences: artist, art educator, art trained, curator/gallerist, writing about and/or interviewing artists, and art conservation. Many knew one or more of the exhibiting artists or their work already. Participants whose Q sorts significantly loaded on Factors 1 and 4 generally had

35. Ibid.

36. Ibid.

37. Ibid. 
much less knowledge and experience of contemporary art than participants in the groups represented by Factors 2, 3 and 5 .

The second key distinguishing feature between the five factors is the negative emotional responses of participants. Factor 1 participants only reported negative emotions for the artworks which they had ranked in their Q sorts with a strong negative emotional response, and only reported positive emotions for the artworks which they had ranked in their $\mathrm{Q}$ sorts with a strong positive emotional response. The negative emotions reported by Factor 1 participants included grief, revulsion, confronted, and despair. For the other four factors the negative emotional ranking of artworks in their $\mathrm{Q}$ sorts did not align neatly with reported negative emotions when explaining their ranking.

In Factor 2, participants ranked with a strong negative emotional response only those artworks which did not engage them or which they made them feel annoyed, angry or revulsion. The artworks which elicited other negative emotions were ranked with a strong positive emotional response in their $\mathrm{Q}$ sorts because those artworks had succeeded in engaging them. That was seen as a very positive experience despite the negative emotions.

For Factor 3 participants this aspect was present but less pronounced. One participant observed: 'I like to be challenged and I like to feel a little bit unsettled and I like to examine and explore how I feel and how that makes me feel and what that makes me think, so generally if an artwork does that I feel positively about it.' Like Factor 2, artworks which did not engage them were ranked negatively in the $\mathrm{Q}$ sort. Otherwise these participants reported mainly positive emotions for the artworks they ranked positively in the $Q$ sort and mainly negative emotions for the artworks which elicited strong negative emotional responses in the $\mathrm{Q}$ sort.

Factor 4 participants, like Factor 1, had less experience of contemporary art, but their explanations of their negative emotional responses were different. The artworks which they ranked with a strong negative emotional response in their $Q$ sorts included ones that did not engage them, were even perceived as a 'waste of space' and having 'no value'. Also ranked negatively were works which they didn't like, which made them uncomfortable. They did not have the same kinds of negative emotions as Factor 1 participants.

Finally, although Factor 5 participants had similar experience of contemporary art as Factors 2 and 3, unlike Factors 2 and 3 they did not describe as unengaging the artworks to which they had given strong negative emotional responses in their Q sorts. Instead, like Factor 1, they tended to report negative emotions for the artworks ranked negatively in the $Q$ sorts.

In summary, Factors 1 (inexperienced with contemporary art) and 5 (experienced) both associated positive emotions with positive $Q$ sort ranking and negative emotions with negative $Q$ sort ranking. Factors 4 (inexperienced) and 3 (experienced) both associated positive emotions with positive $\mathrm{Q}$ sort ranking while unengaging artworks as well as negative emotions received a negative $Q$ 
sort ranking. Factor 2 (experienced) was the only one which associated both positive and negative emotions with positive $Q$ sorting and unengaging artworks as well as negative emotions with negative $Q$ sorting.

Only $40 \%$ of the variance between the $Q$ sorts was explained by the five factors identified. Therefore as well as confirming that there are commonalities in groups of participants, this study affirms that personal characteristics of viewers contribute to a unique experience of art and emotional response to artworks. ${ }^{38}$ Examples of personal influences which participants expressly mentioned in interview were a childhood fear of thunderstorms, a love of estuaries, an association with an advertising campaign, a strong dislike of anything decaying, and personal opinion about the dairy industry. Further analysis of the explanations which participants gave for their emotional responses is expected to shed some light on these influences.

Another personal influence at play is familiarity with the location shown. The local artists did not necessarily ground their work in local environments and local places were not always recognisable as such. In interview, either in explaining the emotional responses in the $\mathrm{Q}$ sorts or in answering subsequent questions, seven participants from all five factors mentioned recognising locations in one or more of seven of the artworks. With one exception this recognition contributed to a strong positive emotional experience for these participants. For example, one participant reported 'it's my home so immediately I felt comforted by that familiarity', while another enjoyed hearing familiar sounds, and a third described kayaking around the coastline depicted. The exception was a participant for whom the local context of two artworks accentuated their negative emotional response: 'for me it happens in the Otago Harbour so it happens right where I live'.

Despite doing the $\mathrm{Q}$ sort within three weeks of seeing the exhibition, some participants could not remember all of the artworks. Participants tended to assume that if they could not remember an artwork then it had not engaged them, which resulted in some participants giving that work a negative emotional response. Reference to a map of the exhibition spaces during interview revealed that some participants had not seen all of the artworks in the exhibition. Some of the photographs used for the $Q$ sort were not good representations of the artworks, which did not matter provided the photographs sufficed to remind participants of the artworks themselves. However, participants were required to sort all of the 54 photographs of the artworks, even if the participant had not seen or could not remember all of the artworks. Participants had to rely upon the representations of the artworks in the photographs instead and this disadvantaged some works, particularly video works, sound works, and multiple works by the same artist exhibited and photographed together. This problem could have been

38. Gauzente and Good, "Q Methodology, William Stephenson and Postdisciplinarity," 2019. 
reduced if the exhibition layout had been simpler and if participants had been provided with a map of the exhibition spaces at recruitment and encouraged to see all the artworks.

Two thirds of participants in this study had considerable prior experience with contemporary art, visiting contemporary art exhibitions once or twice per month, and many of these had other relevant experience as well. Further research into negative emotional responses to contemporary art would benefit from having a higher proportion of less experienced participants. This could perhaps be achieved by having an exhibition venue at a community centre or other location more likely to attract passers-by.

Three participants took the opportunity during interview to comment on the role of environmental art. One felt that environmental art with a strong explicit message as in Figure 4 was 'preaching to the choir essentially with these messages' - it would not change people's views and might even do 'more harm than good by turning people away'. Conversely, another felt that 'we're beyond this kind of subtlety of things and I don't know if that's actually going to be a strategy that works,' while also acknowledging that 'people don't like being shouted at'. The third commented 'if you present people with work that's so depressing and hard to understand and like hard to comprehend they just want to walk away'. As in the children's story of Goldilocks and the Three Bears, it is hard for artists and curators to get environmental art 'just right' to engage audiences effectively when emotional responses differ so markedly.

\section{Conclusion}

Using Q methodology with images of artworks has been an effective way of investigating emotional responses to artworks in an exhibition of environmental art. Q methodology therefore provides another tool for researchers seeking to evaluate the impact of exhibited artworks.

The statistical analysis of the $25 \mathrm{Q}$ sorts of 54 photographs of artworks, grouping participants who share similar emotional responses to all of the artworks in the exhibition, identified five different factors or perspectives. The explanations provided by participants for their four strongest negative emotional responses to the artworks and four strongest positive emotional responses revealed differences in the ways in which they perceived the negative emotions they experienced in response to the artworks. The level of participants' prior experience with contemporary art and the differing perceptions of negative emotions together explain these five factors. This study therefore suggests that negative emotions, and how those negative emotions are perceived, are an important influence for people's experience of exhibited contemporary art. This requires further research.

Participants reported a wide range of emotions, including mixed positive and negative emotions to some artworks. The variety of emotions experienced in 
response to contemporary art also warrants further research. For curators of environmental artworks seeking to engage the public, the different group responses to the three signature artworks here suggest that a variety of artists and artworks works well. It is also advantageous for engagement to include both subtle and explicit environmental artworks, and works that are identifiably local.

\section{Acknowledgements}

Support for this research from Bridie Lonie and Prof Leoni Schmidt at Otago Polytechnic is gratefully acknowledged.

\section{References}

Aragón, Carolina, Jane Buxton, and Elisabeth Hamin Infield. "The Role of Landscape Installations in Climate Change Communication." Landscape and Urban Planning 189 (2019): 11-14.

Beck, Paula D. "Using Works of Art to Give a Voice to Culturally Diverse Students: QMethodology Study." Journal for Leadership and Instruction 16, no. 2 (2017): 18-25.

Bouman, Thijs, Mark Verschoor, Casper J. Albers, Gisela Böhm, Stephen D. Fisher, Wouter Poortinga, Lorraine Whitmarsh, and Linda Steg. "When Worry About Climate Change Leads to Climate Action: How Values, Worry and Personal Responsibility Relate to Various Climate Actions." Global Environmental Change 62 (2020): 102061.

Burke, Miriam, David Ockwell, and Lorraine Whitmarsh. "Participatory Arts and Affective Engagement with Climate Change: The Missing Link in Achieving Climate Compatible Behaviour Change?" Global Environmental Change 49 (2018): 95-105.

Chapman, Daniel A., Adam Corner, Robin Webster, and Ezra M. Markowitz. "Climate Visuals: A Mixed Methods Investigation of Public Perceptions of Climate Images in Three Countries." Global Environmental Change 41 (2016): 172-182.

Curtis, David J., Nick Reid, and Ian Reeve. "Towards Ecological Sustainability: Observations on the Role of the Arts." SAPIENS 7, no. 1 (2014).

Duxbury, Lesley. "A Change in the Climate: New Interpretations and Perceptions of Climate Change Through Artistic Interventions and Representations." Weather Climate and Society 2, no. 4 (2010): 294-299.

Galafassi, Diego, Sacha Kagan, Manjana Milkoreit, María Heras, Chantal Bilodeau, Sadhbh Juarez Bourke, Andrew Merrie, Leonie Guerrero, Guðrún Pétursdóttir, and Joan David Tàbara. "“Raising the Temperature": The Arts on a Warming Planet." Current Opinion in Environmental Sustainability 31 (2018): 71-79.

Gauzente, Claire, and James M.M. Good. "Q Methodology, William Stephenson and Postdisciplinarity." In Postdisciplinary Knowledge, edited by Tomas Pernecky. Abingdon, Oxon: Routledge, 2019, 165-182.

Giannachi, Gabriella. "Representing, Performing and Mitigating Climate Change in Contemporary Art Practice." Leonardo 45, no. 2 (2012): 124-131.

Hahn, Ulrike, and Pauwke Berkers. Visualizing Climate Change: An Exploratory Study of the Effectiveness of Artistic Information Visualizations. World Art, 4 June 2020, 1-25. 
Lonie, Bridie. In The Complete Entanglement of Everything Exhibition Catalogue, by Dunedin School of Art. Dunedin, NZ: Otago Polytechnic, 2020.

Lorenzoni, Irene, Sophie Nicholson-Cole, and Lorraine Whitmarsh. "Barriers Perceived to Engaging with Climate Change among the UK Public and Their Policy Implications." Global Environmental Change 17, no. 3-4 (2007): 445-459.

Merrick, Kath. The Power of Art to Engage the Public on the Impacts of Climate Change on the Coast. Western Australia: Curtin University, 2011.

Moser, Susanne C. "Communicating Adaptation to Climate Change: The Art and Science of Public Engagement when Climate Change Comes Home." Wiley Interdisciplinary Reviews: Climate Change 5, no. 3 (2014): 337-358.

O'Neill, Saffron, and Sophie Nicholson-Cole. "“Fear Won't Do It": Promoting Positive Engagement with Climate Change Through Visual and Iconic Representations." Science Communication 30, no. 3 (2009): 355-379.

Ojala, Maria. "Hope and Climate Change: The Importance of Hope for Environmental Engagement Among Young People." Environmental Education Research 18, no. 5 (2012): 625-642.

Rice, Ronald E., Stacy Rebich-Hespanha, and Huiru Zhu. "Communicating About Climate Change Through Art and Science." In Climate Change, Media \& Culture: Critical Issues in Global Environmental Communication, edited by Juliet Pinto, Robert E. Jr. Gutsche, and Paola Prado. Bingley, UK: Emerald Publishing Limited, 2019, 129-154.

Roeser, Sabine. "Risk Communication, Public Engagement, and Climate Change: A Role for Emotions." Risk Analysis 32, no. 6 (2012): 1033-1040.

Roosen, Liselotte J., Christian A. Klöckner, and Janet K. Swim. "Visual Art as a Way to Communicate Climate Change: A Psychological Perspective on Climate ChangeRelated Art." World Art 8, no. 1 (2018): 85-110.

Schmolck, Peter. PQMethod. Retrieved from: http://schmolck.org/qmethod/. [Accessed 30 October 2020.]

Schultz, Tracy, Kelly Fielding, and Fiona Newton. "Images That Engage People With Sustainable Urban Water Management." Science Communication 40, no. 2 (2018): 199227.

Sleenhoff, Susanne, and Patricia Osseweijer. "How People Feel Their Engagement Can Have Efficacy for a Bio-Based Society." Public Understanding of Science 25, no. 6 (2016): 719-736.

Sommer, Laura Kim, and Christian Andreas Klöckner. "Does Activist Art Have the Capacity to Raise Awareness in Audiences? - A Study on Climate Change Art at the ArtCOP21 Event in Paris." Psychology of Aesthetics, Creativity, and the Arts, 2019. https://doi.org/10.1037/aca0000247.

Sommer, Laura Kim, Janet Kay Swim, Anna Keller, and Christian Andreas Klöckner. "'Pollution Pods": The Merging of Art and Psychology to Engage the Public in Climate Change." Global Environmental Change 59 (2019): 101992.

Statistics NZ Tatauranga Aotearoa. 2018 Census Place Summaries - Dunedin City. Retrieved from: https://www.stats.govt.nz/tools/2018-census-place-sum maries/dunedin-city. [Accessed 7 January 2021.]

Stephenson, W. "The Inverted Factor Technique." British Journal of Psychology. General Section 26, no. 4 (1936): 344-361.

Tinio, Pablo P L, and Andreas Gartus. "Characterizing the Emotional Response to Art Beyond Pleasure: Correspondence Between the Emotional Characteristics of 
Vol. 9, No. 3

Brook: Evaluating the Emotional Impact of Environmental...

Artworks and Viewers' Emotional Responses." In The Arts and The Brain: Psychology and Physiology Beyond Pleasure, edited by Julia F. Christensen and Antoni Gomila. Progress in Brain Research. San Diego: Elsevier Science \& Technology, 2018, 237: 319342.

Watts, Simon, and Paul Stenner. Doing Q Methodological Research: Theory, Method and Interpretation. Los Angeles, [Calif.], London: SAGE, 2012. 